Bài báo khoa học

\title{
Xu thế biến đổi của các yếu tố khí hậu và kịch bản biến đổi khí hậu tỉnh Ninh Thuận
}

\section{Nguyễn Văn Hồng ${ }^{*}$, Nguyễn Thị Cầm Mi ${ }^{1}$}

${ }^{1}$ Phân Viện Khoa học Khí tượng Thủy văn và Biến đổi khí hậu; nguyenvanhong79@gmail.com; nguyenthicammi2007@gmail.com

*Tác giả liên hệ: nguyenvanhong79@gmail.com; Tel.: +84-913613206

Ban Biên tập nhận bài: 8/4/2021; Ngày phản biện xong: 21/5/2021; Ngày đăng bài: $25 / 7 / 2021$

Tóm tắt: Bài báo trình bày xu thế biến đổi các yếu tố khí hậu (nhiệt độ, lượng mưa) tại tỉnh Ninh Thuận. Phương pháp thống kê và hàm hồi quy tuyến tính được sử dụng để phân tích chuỗi số liệu quan trắc tại trạm Phan Rang giai đoạn 1993-2019. Kết quả cho thấy các yếu tố khí hậu đều có xu thế tăng: nhiệt độ trung bình nhiều năm có xu thế tăng $0,012^{\circ} \mathrm{C} /$ năm, nhiệt độ tối cao tăng $0,017^{\circ} \mathrm{C} /$ năm, nhiệt độ tối thấp tăng $0,01^{\circ} \mathrm{C} /$ năm, lượng mưa tăng 4,44 $\mathrm{mm} /$ năm. Theo kịch bản RCP4.5 và RCP8.5, nhiệt độ trung bình tại Ninh Thuận có xu thế tăng qua các năm 2025,2030, 2050 và 2100 . Về lượng mưa trung bình theo kịch bản RCP4.5 có xu thế tăng. Đối với kịch bản RCP8.5 lượng mưa tăng vào năm 2025, 2030 và giảm và năm 2050, 2100.

Từ khóa: Khí hậu; Xu thế; Kịch bản biến đổi khí hậu RCP4.5, RCP8.5.

\section{Mở đầu}

Ninh Thuận là tỉnh thuộc khu vực Nam Trung Bộ, do đặc thù về địa lý và địa hình, Ninh Thuận thường xuyên chịu ảnh hường của thiên tai và biến đổi khí hậu $(\mathrm{B} Đ K H)$. Trong những thập kỷ gần đây, Ninh Thuận chịu tác động lớn của các hiện tượng thời tiết cực đoan như hạn hán, hoang mạc hóa, khô nóng, bão, mưa lớn gây lũ, ngập lụt. Để có những nhận định phù hợp với tình hình BĐKH hiện nay, việc đánh giá xu thế biến đồi các yếu tố khí hậu đến thời điểm hiện tại giúp có cái nhìn khách quan về những diễn biến khí hậu đang diễn ra trong quá khứ. Tuy nhiên, các kết quả đánh giá xu thế và kịch bản $\mathrm{BĐKH}$ chi tiết cho tỉnh Ninh Thuận còn hạn chế, các nghiên cứu được thực hiện chủ yếu ở quy mô quốc gia và khu vực dựa trên các kịch bản phát thải khí nhà kính hoặc đường phân bố nồng độ khí nhà kính đại diện, tỉnh Ninh Thuận chỉ là một phần rất nhỏ [1-5].

Như vậy, có thể thấy việc nghiên cứu xu thế các yếu tố khí tượng và kịch bản BĐKH trong quá khứ và dự tính $\mathrm{BĐKH}$ trong thế kỷ 21 cho tỉnh Ninh Thuận có ý nghĩa khoa học, thực tiễn, đây là một phần kết quả nghiên cứu của 02 nhiệm vụ: "Xây dựng, cập nhật kế hoạch hành động ứng phó với BĐKH giai đoạn 2021-2030, tầm nhìn đến 2050 và Đánh giá khí hậu của tỉnh Ninh Thuận”. Bài báo trình bày kết quả đánh giá xu thế các yếu tố khí hậu và kịch bản $B Đ K H$ tại Ninh Thuận nhằm cung cấp các thông tin khí hậu hiện tại, dự báo, cảnh báo kịp thời và hiệu quả những diễn biến khí hậu trong tương lai là biện pháp giảm thiểu những tác động do biến đổi khí hậu gây ra đồng thời phục vụ quy hoạch sản xuất, phát triển kinh tế-xã hội và phòng chống thiên tai trên địa bàn tỉnh.

\section{Phương pháp nghiên cứu}

\subsection{Khu vục nghiên cứu}


Ninh Thuận là một tỉnh ven biển thuộc khu vực Nam Trung Bộ, địa hình của Ninh Thuận rất đa dạng và phức tạp, thấp dần từ Tây sang Đông, từ Bắc vào Nam, vừa có địa hình miền núi vừa có địa hình trung du và đồng bằng ven biển. Phía Bắc giáp tỉnh Khánh Hòa, phía Nam giáp tỉnh Bình Thuận, phía Tây giáp tỉnh Lâm Đồng, phía Đông giáp Biển Đông (Hình 1).

Ninh Thuận có đường bờ biển dài $105 \mathrm{~km}$, diện tích vùng lãnh hải trên $18.000 \mathrm{~km}^{2}$. Trung tâm tỉnh là thành phố Phang Rang-Tháp Chàm. Ninh Thuận hiện có 7 đơn vị hành chính bao gồm huyện Bắc Ái, huyện Ninh Sơn, huyện Ninh Phước, huyện Thuận Nam, huyện Thuận Bắc, Huyện Ninh Hải và Thành phố Phang Rang-Tháp Chàm. Ninh Thuận có cả đường sắt Bắc Nam và quốc lộ $1 \mathrm{~A}$ đi qua. Đồng thời có Quốc lộ 27 nối liền với các tỉnh Tây Nguyên.

Khí hậu tỉnh Ninh Thuận là khí hậu nhiệt đới gió mùa với 2 mùa rõ rệt là mùa khô và mùa mưa, tương ứng với hai thời kỳ gió mùa Tây Nam và gió mùa Đông Bắc. Mùa khô bắt đầu từ tháng 1 và kết thúc vào tháng 8 , mùa mưa bắt đầu từ tháng 9 và kết thúc vào tháng 12 . Thủy văn Ninh Thuận cũng có 2 mùa là mùa kiệt và mùa lũ, tương ứng với mùa khô và mùa mưa của khí hậu [6 -9].

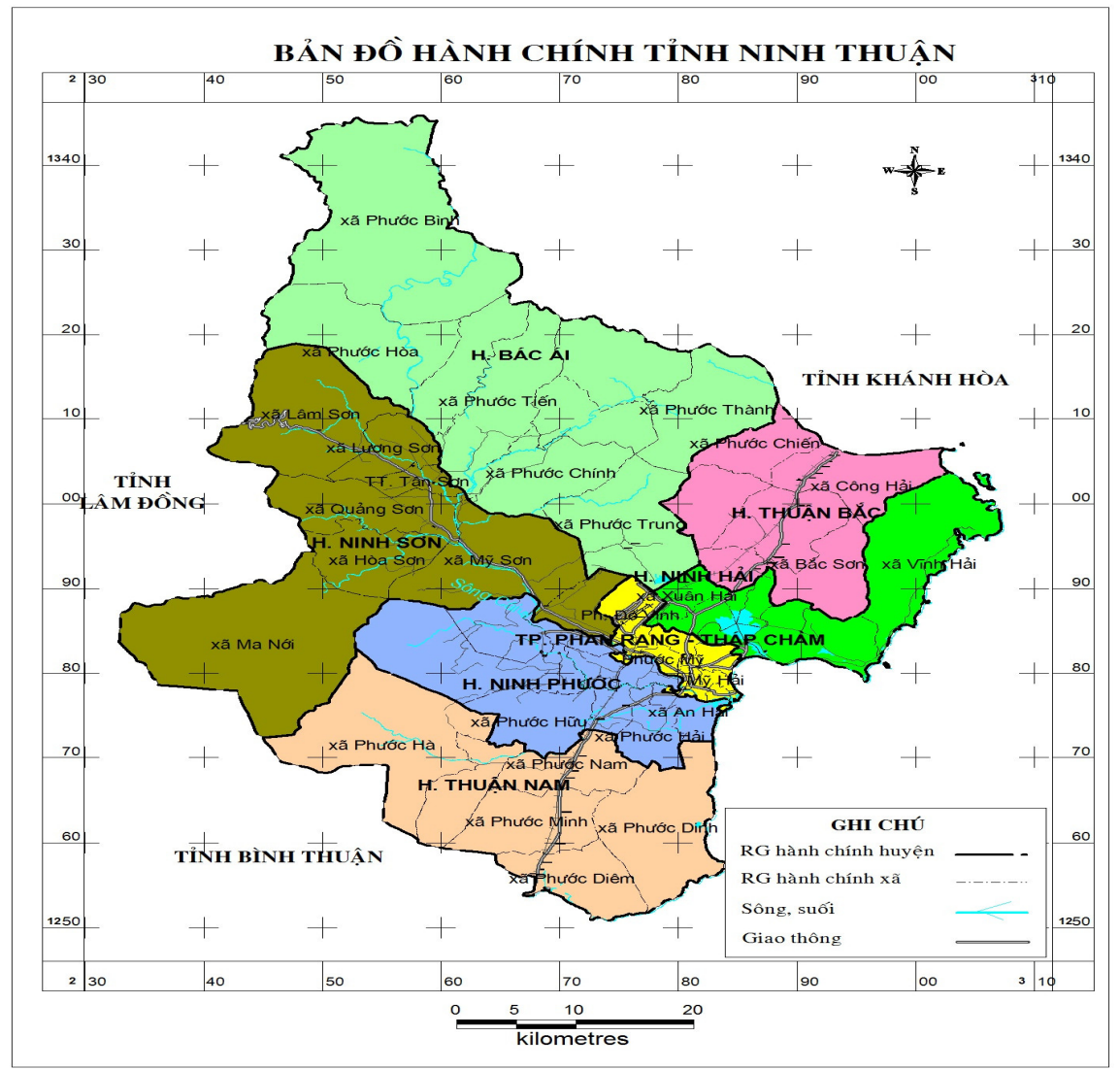

Hình 1. Bản đồ hành chính tỉnh Ninh Thuận.

\subsection{Phưong pháp nghiên cúu}

\subsubsection{Phương pháp đánh giá xu thế}

Tính toán giá trị trung bình của chuỗi số liệu

$$
\mu=\frac{1}{n} \sum_{\mathrm{k}=1}^{\mathrm{n}} \mathrm{x}_{\mathrm{i}}
$$

Phương pháp hồi quy xu thế được đề cập là phân tích hàm hồi quy giữa biến phụ thuộc $\mathrm{x}$ và biến thời gian $\mathrm{t}, \mathrm{x}=\mathrm{f}(\mathrm{t})$. Nếu $\mathrm{f}(\mathrm{t})$ là một hàm tuyến tính thì được gọi là có xu thế biến đổi tuyến tính. Để nghiên cứu xu thế biến đổi tuyến tính ta thành lập phương trình hồi quy [10-11].

$$
x(t)=a t+b
$$


Trong đó $\mathrm{x}$ là giá trị của hàm, $\mathrm{t}$ : biến thời gian, $\mathrm{a}, \mathrm{b}$ : hệ số hồi quy, hệ số $\mathrm{a}$ cho biết hướng dốc của đường hồi quy (xu thế biến đồi tăng hay giảm theo thời gian).

Xu thế tăng giảm của $x$ theo $t$ được đánh giá trên cơ sở xét dấu và độ lớn của hệ số góc $a$. Dấu của hệ số a xác định xu thế tăng (khi a $>0$ ) hoặc giảm (khi a $<0)$, còn trị tuyệt đối của a cho biết mức độ tăng giảm của dữ liệu theo biến đổi của thời gian $\mathrm{t}$.

Các hệ số $\mathrm{a}, \mathrm{b}$ được xác định theo công thức:

$$
\mathrm{a}=\frac{\sum_{\mathrm{t}=1}^{\mathrm{n}}\left(\mathrm{x}_{\mathrm{t}}-\overline{\mathrm{x}}\right)(\mathrm{t}-\overline{\mathrm{t}})}{\sqrt{\sum_{\mathrm{t}=1}^{\mathrm{n}}\left(\mathrm{x}_{\mathrm{t}}-\overline{\mathrm{x}}\right)^{2}(\mathrm{t}-\overline{\mathrm{t}})^{2}}} ; \mathrm{b}=\overline{\mathrm{x}}-\mathrm{a} \overline{\mathrm{t}} ; \overline{\mathrm{x}}=\frac{1}{\mathrm{n}} \sum_{\mathrm{t}=1}^{\mathrm{n}} \mathrm{x}_{\mathrm{t}} ; \overline{\mathrm{t}}=\frac{1}{\mathrm{n}} \sum_{\mathrm{t}=1}^{\mathrm{n}} \mathrm{t}
$$

Trong đó $\overline{\mathrm{x}}, \overline{\mathrm{t}}$ là trung bình số học của $\mathrm{x}$ và $\mathrm{t}$.

\subsubsection{Phương pháp xây dựng kịch bản}

Mô hình khí hậu toàn cầu và khu vực là những công cụ chính được sử dụng để đánh giá xu thế biến đổi và diễn biến khí hậu tương lai. Kịch bản biến đổi khí hậu ở khu vực tỉnh Ninh Thuận được xây dựng dựa trên bốn mô hình khí hậu khu vực (PRECIS, CCAM, RegCM, clWRF) với tổng cộng 12 phương án tính toán được thực hiện, sử dụng kết quả đầu vào từ các mô hình toàn cầu khác.

Dựa trên các kết quả đánh giá của 4 mô hình khí hậu, kịch bản biến đổi khí hậu tỉnh Ninh Thuận đối với nhiệt độ được xây dựng theo kết quả tính toán từ 8 phương án của 3 mô hình (3 phương án CCAM, 3 phương án PRECIS và 1 phương án clWRF), kịch bản biến đổi với lượng mưa được xây dựng dựa trên kết quả tính toán từ 3 phương án của mô hình PRECIS [12-17].

\subsubsection{Thu thập dữ liệu đầu vào}

Việc đánh giá sự biến đổi của các yếu tố khí hậu được sử dụng số liệu tại trạm Phan Rang (tỉnh Ninh Thuận) trong giai đoạn từ năm 1993-2019.

\section{Kết quả và thảo luận}

\subsection{Xu thế biến đổi của các yếu tố khí hậu}

\subsubsection{Nhiệt độ}

Từ chuỗi số liệu quan trắc nhiệt độ tại trạm Phan Rang giai đoạn 1993-2019, nhiệt độ trung bình hằng năm vào là $27,2^{\circ} \mathrm{C}$. Nhiệt độ dao động từ $24,9-28,9^{\circ} \mathrm{C}$, trong đó tháng $\mathrm{I}$ có nhiệt độ trung bình thấp nhất với giá trị là $24,9^{\circ} \mathrm{C}$. Tháng $\mathrm{V}$ và $\mathrm{VI}$ có nhiệt độ trung bình cao nhất với giá trị là $28,9^{\circ} \mathrm{C}$ (Hình 2). Về xu thế nhiệt độ trung bình giai đoạn 1993-2019 tại trạm Phan Rang có xu thế tăng khoảng $0,012^{\circ} \mathrm{C} /$ năm (Hình 3).

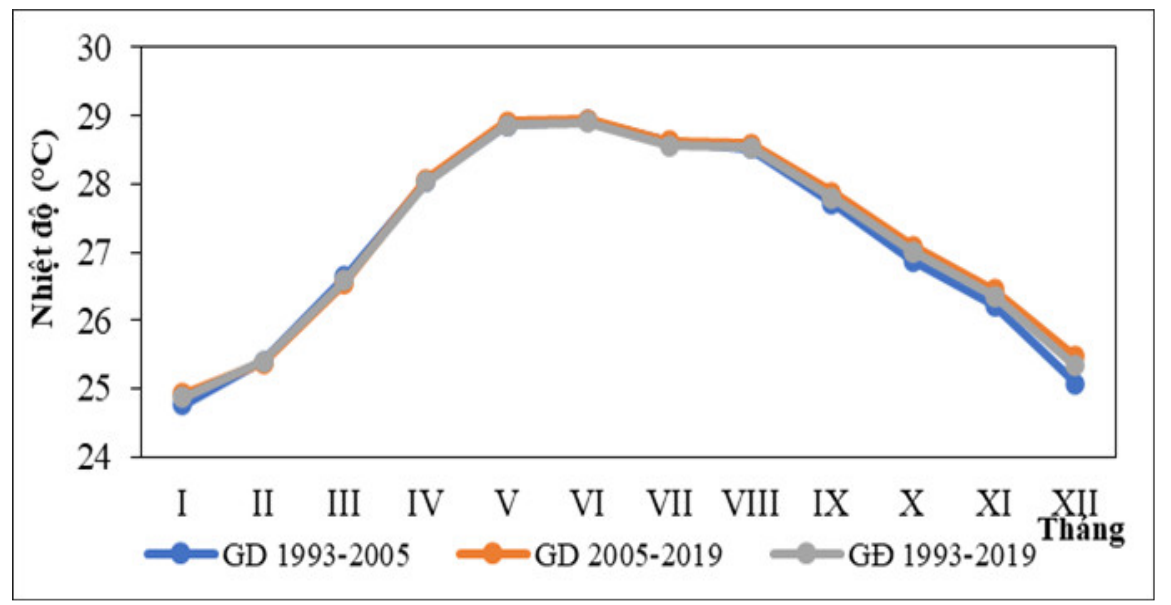

Hình 2. Biến thiên nhiệt độ trung bình theo tháng giai đoạn 1993-2019 tại trạm Phan Rang. 


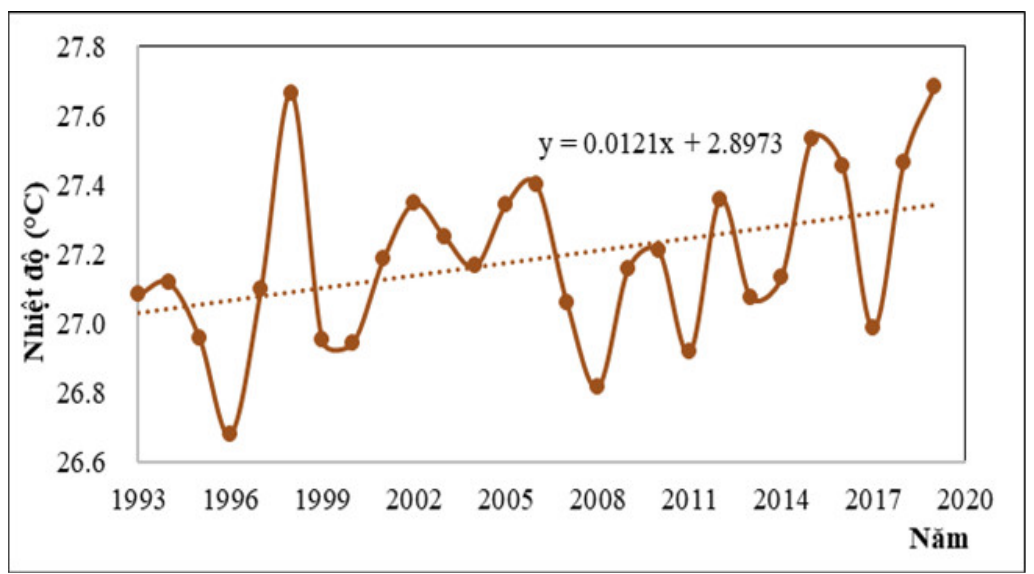

Hình 3. Xu thế biến đổi nhiệt độ trung bình năm giai đoạn 1993-2019 tại trạm Phan Rang.

Trong giai đoạn 1993-2019, nhiệt độ tối cao trung bình tại trạm Phan Rang là $31,8^{\circ} \mathrm{C}$. Trong đó, tháng XII có nhiệt độ tối cao trung bình thấp nhất với giá trị là $28,8^{\circ} \mathrm{C}$. Tháng VI có nhiệt độ tối cao trung bình cao nhất với giá trị là $34,2^{\circ} \mathrm{C}$ (Hình 4). Về xu thế nhiệt độ tối cao trung bình tại trạm Phan Rang giai đoạn $1993-2019$ có xu thế tăng khoảng $0,017^{\circ} \mathrm{C} /$ năm (Hình 5).

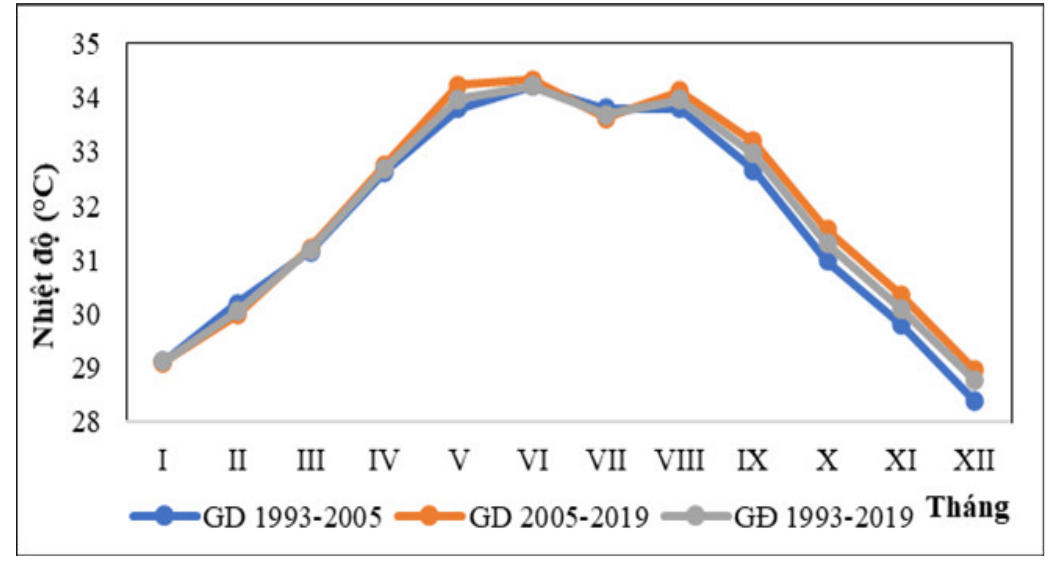

Hình 4. Biến thiên nhiệt độ tối cao trung bình theo tháng giai đoạn 1993-2019 tại trạm Phan Rang.

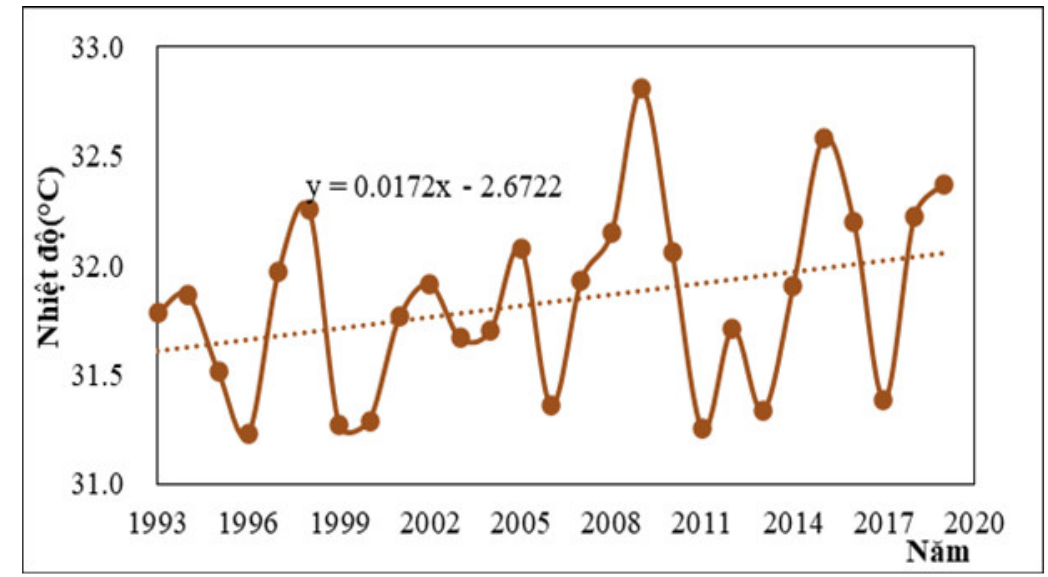

Hình 5. Xu thế biến đổi nhiệt độ tối cao trung bình năm giai đoạn 1993-2019 tại trạm Phan Rang.

Nhiệt độ tối thấp trung bình tại trạm Phan Rang giai đoạn 1993-2019 là 23,80. Trong đó, tháng I, II có nhiệt độ tổi thấp trung bình thấp nhất với giá trị là $21,6^{\circ} \mathrm{C}$. Tháng VI có nhiệt 
độ tối thấp trung bình cao nhất với giá trị là $25,3^{\circ} \mathrm{C}$ (Hình 6$)$. Về xu thế biến đổi nhiệt độ tối thấp trung bình giai đoạn 1993-2019 có xu thế tăng khoảng $0,01^{\circ} \mathrm{C} /$ năm (Hình 7).

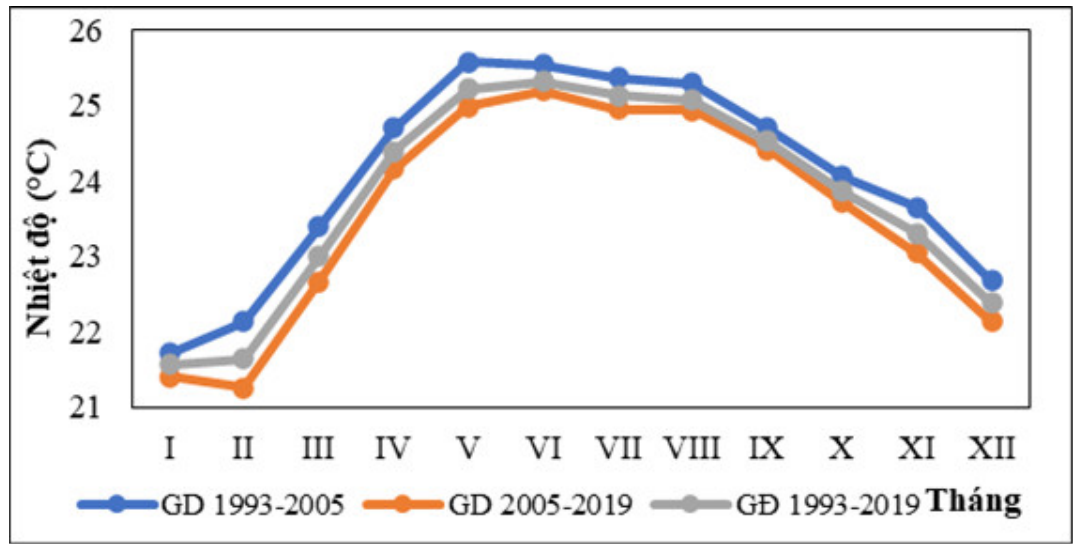

Hình 6. Biến thiên nhiệt độ tối thấp trung bình theo tháng giai đoạn 1993-2019 tại trạm Phan Rang.

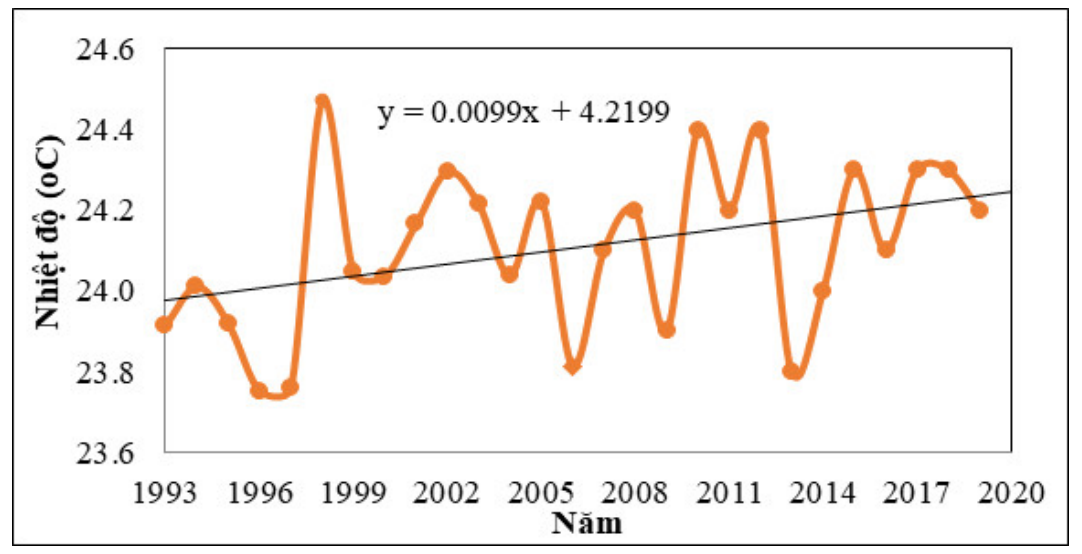

Hình 7. Xu thế biến đổi nhiệt độ tối thấp trung bình năm giai đoạn 1993-2019 tại trạm Phan Rang.

\subsubsection{Lượng mưa}

Từ chuỗi số liệu quan trắc lượng mưa giai đoạn 1993-2019, lượng mưa trung bình nhiều năm tại trạm Phan Rang là $923,8 \mathrm{~mm}$. Lượng mưa đạt cao nhất vào tháng $\mathrm{X}$ với giá trị là $189,0 \mathrm{~mm}$ và thấp nhất vào tháng II với giá trị là $3,2 \mathrm{~mm}$ (Hình 8 ). Về xu thế biến đổi lượng mưa năm tại trạm Phan Rang giai đoạn 1993-2019 có xu thế tăng khoảng 4,44 mm/năm (Hình 9).

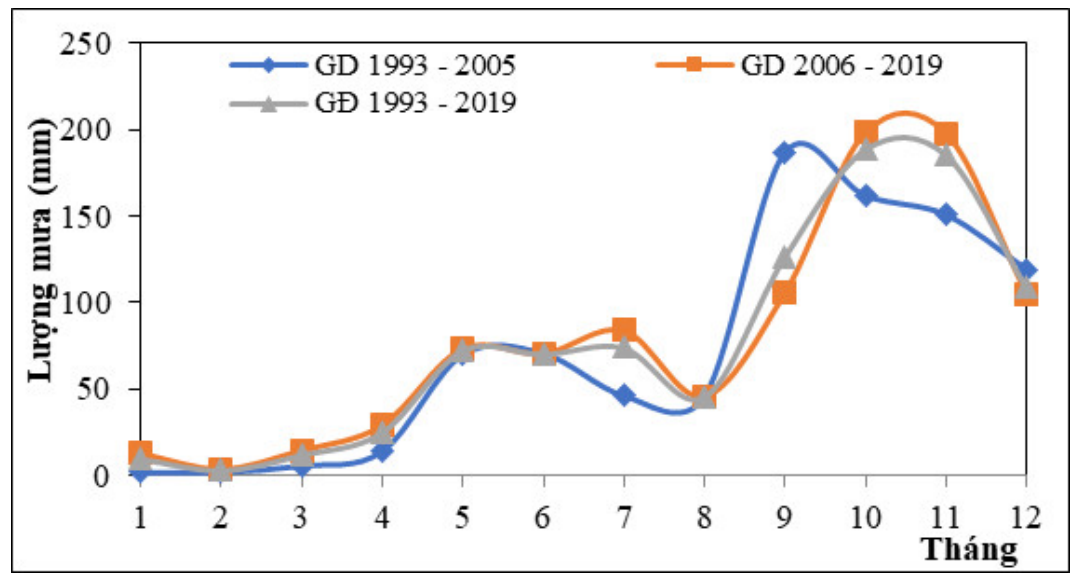

Hình 8. Biến thiên lượng mưa theo tháng các giai đoạn 1993 - 2019 tại trạm Phan Rang. 


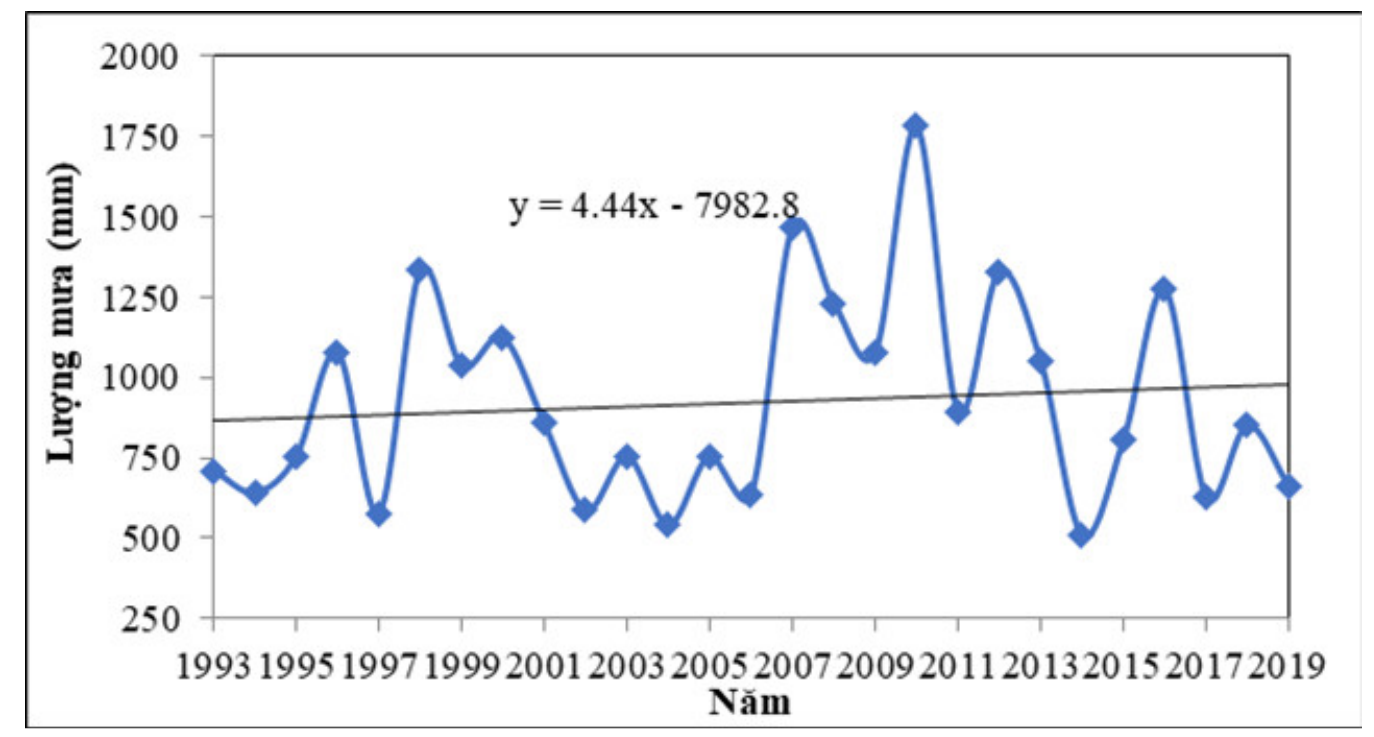

Hình 9. Xu thế biến đổi tổng lượng mưa năm giai đoạn 1993-2019 tại trạm Phan Rang.

\subsection{Kịch bản Biến đổi của các yếu tố khi hậu}

\subsubsection{Kịch bản nhiệt độ}

Theo kịch bản RCP4.5, nhiệt độ trung bình năm 2025 tăng khoảng đồng nhất, khoảng $0,6^{\circ} \mathrm{C}$ giữa các huyện và thành phố trên địa bàn tỉnh Ninh Thuận. Năm 2030, nhiệt độ tăng từ $0,6-0,7^{\circ} \mathrm{C}$, nơi có nhiệt độ cao nhất ở huyện Bắc Ái. Vào năm 2050 , nhiệt độ trung bình tăng đều trong phạm vi toàn tỉnh khoảng $1,4^{\circ} \mathrm{C}$. Đến năm 2100 , sự phân bố nhiệt độ tăng khoảng $1,8-1,9^{\circ} \mathrm{C}$, nhiệt độ tăng cao ở khu vực huyện Bắc Ái và Ninh Sơn. Theo kịch bản RCP8.5, năm 2025 và 2050 nhiệt độ trung bình trên địa bàn tỉnh Ninh Thuận tăng khoảng đồng đều khoảng $0,7^{\circ} \mathrm{C}$. Năm 2050 , nhiệt độ tăng trung bình toàn tỉnh tăng $1,9^{\circ} \mathrm{C}$ và đến năm 2100 nhiệt độ tăng từ $3,3-3,5^{\circ} \mathrm{C}$, nhiệt độ tăng cao ở khu vực huyện Bắc Ái và Ninh Sơn (Hình 10).

\subsubsection{Kịch bản lượng mưa}

Theo kịch bản RCP4.5, năm 2025 lượng mưa trung bình tăng từ 0,2-3,1\% tăng cao nhất ở khu vực huyện Ninh Hải và thấp nhất ở huyện Ninh Phước. Năm 2030, lượng mưa tăng từ 0,2-3,3\% tăng cao ở khu vực huyện Thuận Bắc. Vào năm 2050, lượng mưa phân bố không đều giữa các khu vực, huyện Ninh Sơn, Ninh Phước và thành phố Phan Rang-Tháp Chàm lượng mưa giảm khoảng $0,2 \%$, các huyện còn lại lượng mưa có xu hướng tăng từ $0,7-5,2 \%$. Lượng mưa trung bình cả năm 2100 biến động không đều từ giảm $2,8 \%$ đến tăng $2 \%$. Huyện Ninh Phước là nơi có mức biến đổi lượng mưa giảm nhiều nhất với khoảng $2,8 \%$. Huyện Ninh Hải là nơi có mức biến đổi lượng mưa tăng cao nhất với khoảng 2,0\% (Hình 11a).

Theo kịch bản RCP8.5, năm 2025 lượng mưa trung bình tại Ninh Thuận có tăng từ $3,8-9,1 \%$ và tăng cao ở khu vực huyện Ninh Hải, Thuận Bắc và một phần thành phố Phan Rang-Tháp Chàm. Năm 2030, lượng mưa tăng từ 3,7-9,1\% sự phân bố lượng mưa phân bố tương tự như năm 2025. Năm 2050, lượng mưa có sự phân bố tăng giảm không đồng đều, huyện Ninh Phước có lượng mưa giảm $2,1 \%$, tuy nhiên khu vực huyện Bắc Ái và Thuận Bắc có lượng mưa tăng khoảng 2,5\%. Đến năm 2100 có sự phân bố lượng mưa có xu hướng giảm từ $1,3 \%$ đến $8,9 \%$, huyện Ninh Hải là nơi có lượng mưa giảm ít nhất với khoảng $1,3 \%$, nơi có lượng mưa giảm nhiều nhất là huyện Ninh Phước với khoảng 8,9\% (Hình 11b). 


\section{RCP4.5}
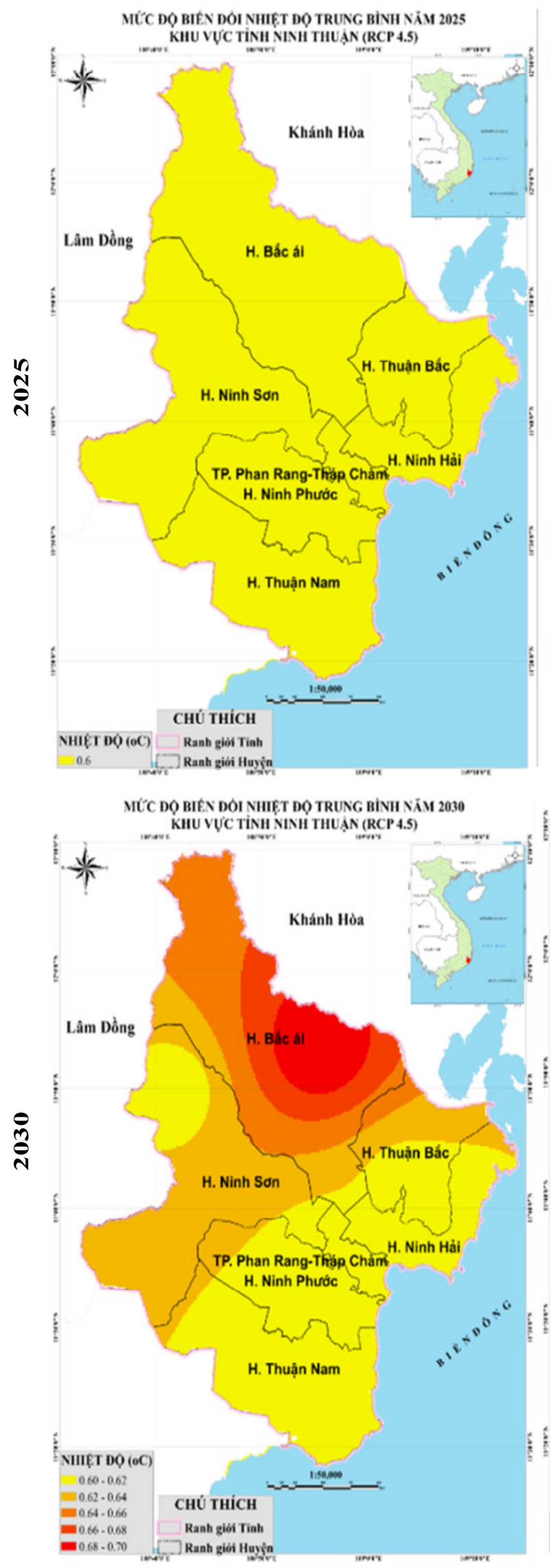

\section{RCP8.5}

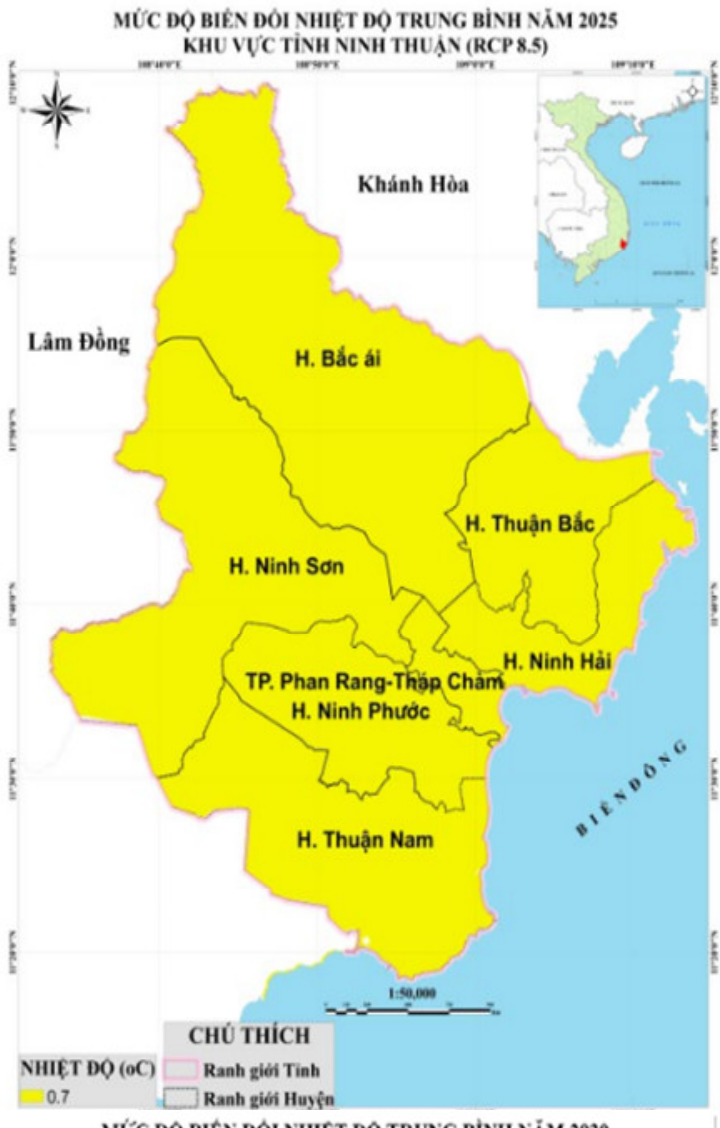

VǗC DO BIEN DÓI NHIET DO TRUNG BINA NÄM 2030 KHU VỰC TINH NINH THUẠN (RCP 8.5)

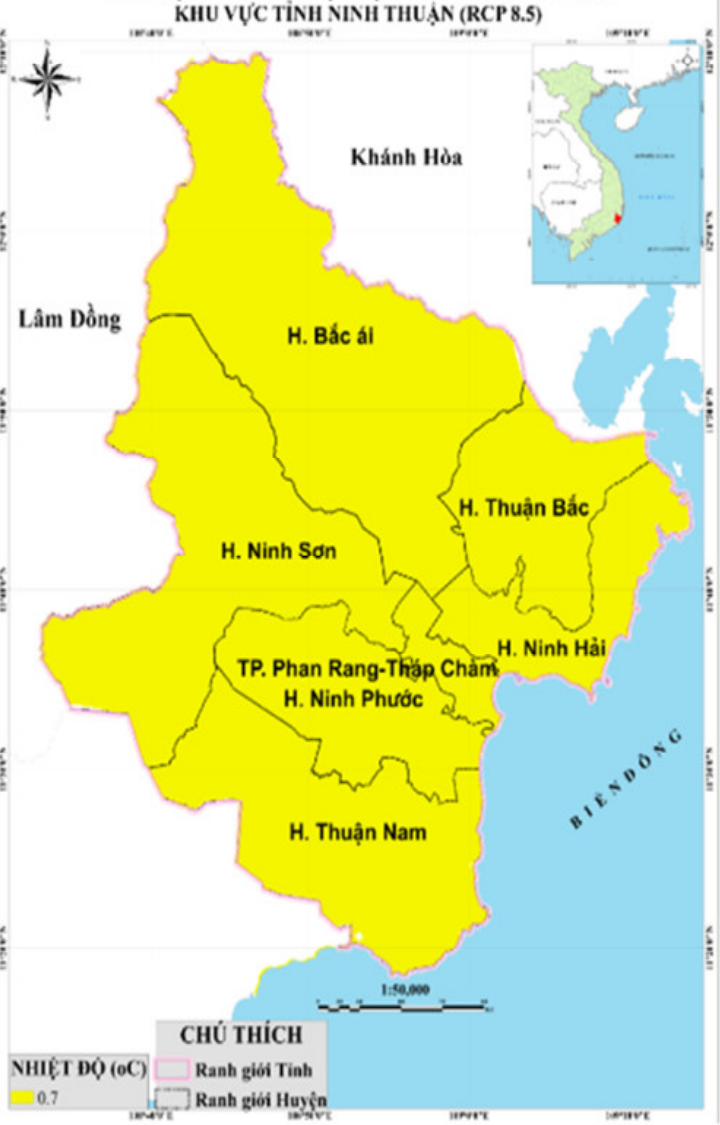

Hình 10. Mức độ biến đổi nhiệt độ trung bình $\left({ }^{\circ} \mathrm{C}\right)$ tỉnh Ninh Thuận theo kịch bản RCP4.5 (trái) và RCP8.5 (phải). 
RCP4.5
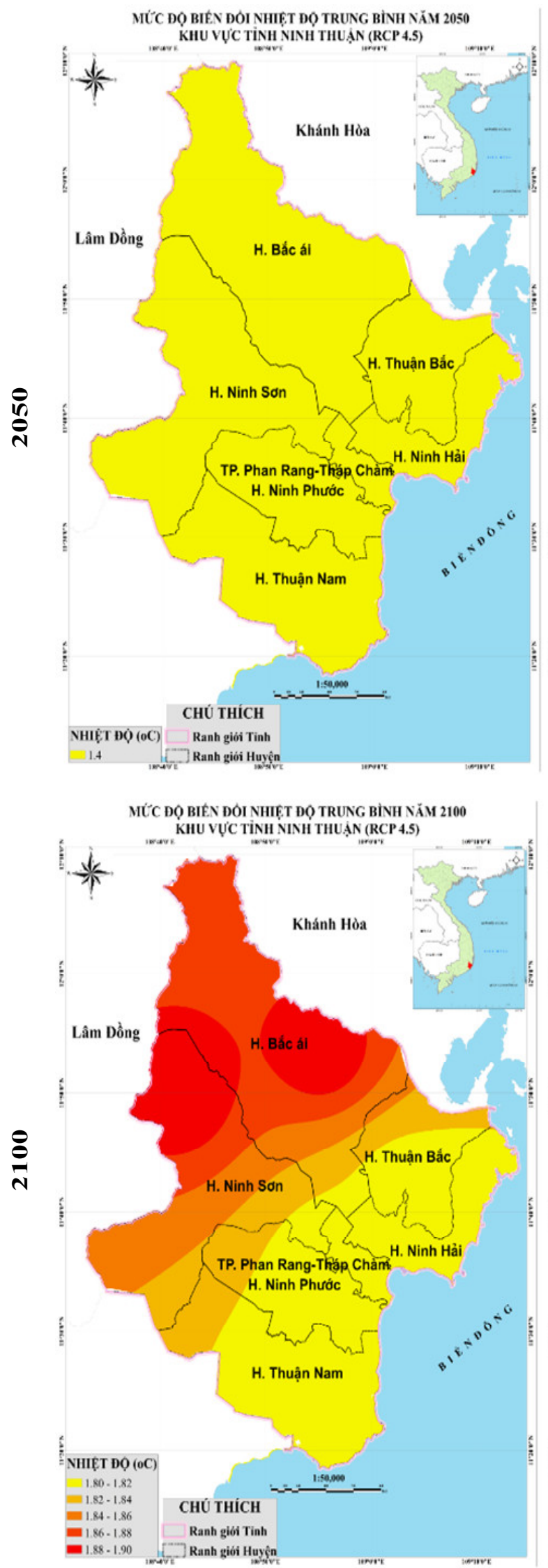

RCP8.5
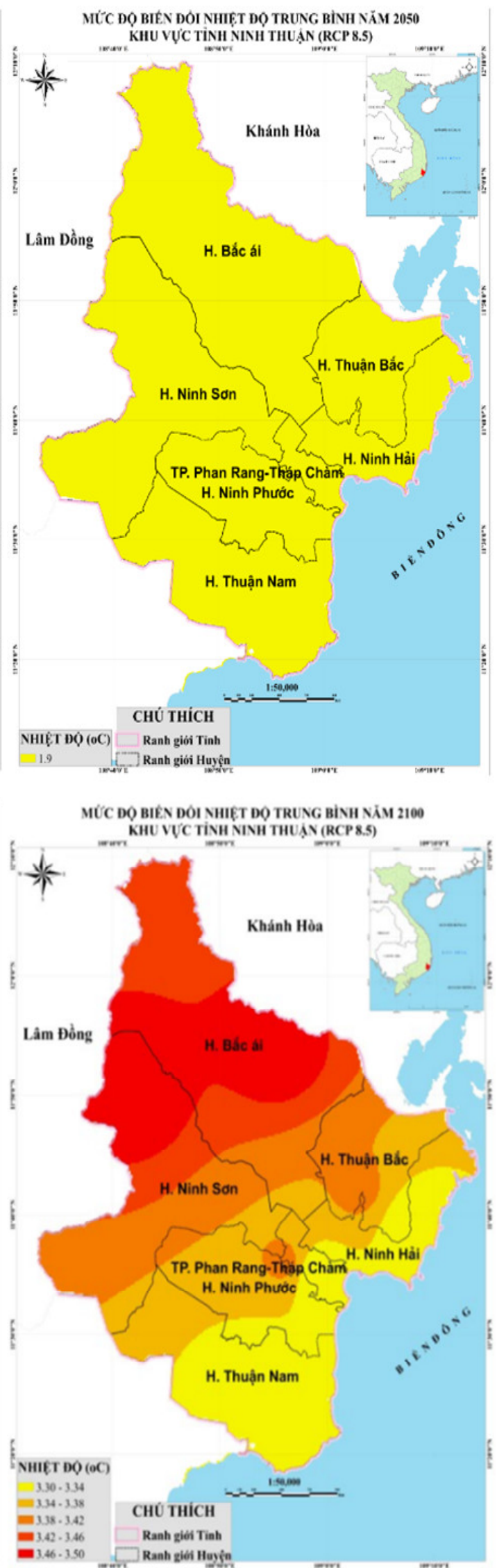

Hình 10. Mức độ biến đổi nhiệt độ trung bình $\left({ }^{\circ} \mathrm{C}\right)$ tỉnh Ninh Thuận theo kịch bản RCP4.5 (trái) và RCP8.5 (phải) (tiếp tục). 

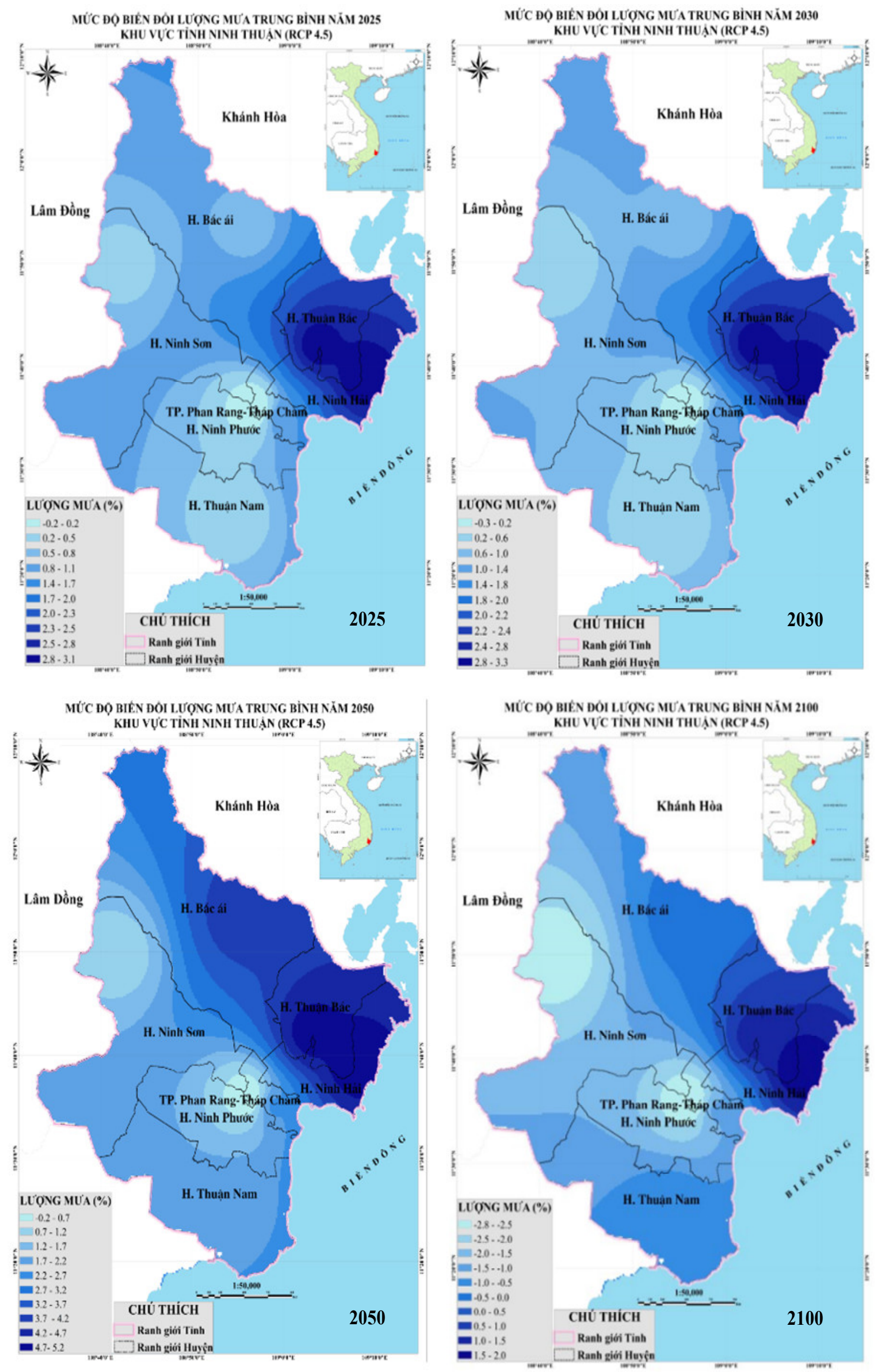

Hình 11a. Mức độ biến đổi lượng mưa năm (mm) tỉnh Ninh Thuận theo kịch bản RCP4.5. 

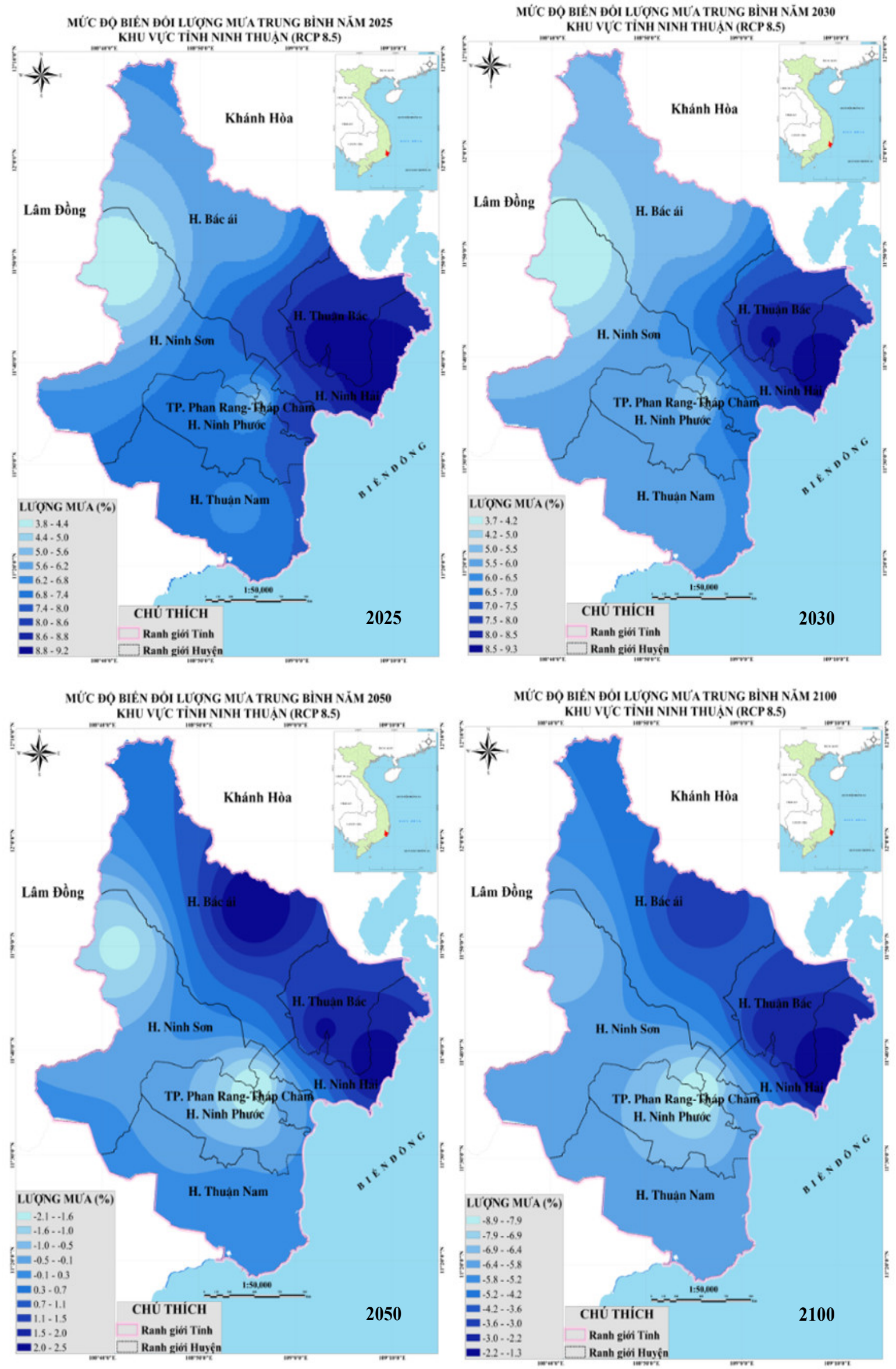

Hình 11b. Mức độ biến đổi lượng mưa năm (mm) tỉnh Ninh Thuận theo kịch bản RCP8.5. 


\section{Kết luận}

Trong giai đoạn 1993-2019, nhiệt độ trung bình ở Ninh Thuận có xu thế tăng xấp xỉ $0,012^{\circ} \mathrm{C} /$ năm, lượng mưa có xu thế tăng $4,4 \mathrm{~mm} /$ năm, số giờ năng có xu thế tăng 0,6 ngày/năm. Nhiệt độ trung bình hằng năm tại trạm Phan Rang là $27,2^{\circ} \mathrm{C}$. Trong đó, tháng I có nhiệt độ trung bình thấp nhất với giá trị là $24,9^{\circ} \mathrm{C}$. Tháng $\mathrm{V}$ và VI có nhiệt độ trung bình cao nhất với giá trị là $28,9^{\circ} \mathrm{C}$. Nhiệt độ trung bình hằng năm tại trạm Phan Rang dao động quanh giá trị trung bình với biên độ $1,0^{\circ} \mathrm{C}$. Tháng có biên độ dao động cao nhất là tháng VI với mức dao động $4,0^{\circ} \mathrm{C}$ quanh giá trị trung bình. Tháng có biên độ dao động thấp nhất là tháng 10 với mức dao động $1,4^{\circ} \mathrm{C}$. Lượng mưa trung bình nhiều năm tại Phan Rang là $923,8 \mathrm{~mm}$. Tháng có biên độ dao động cao nhất là tháng XII với mức dao động $618,0 \mathrm{~mm}$ quanh giá trị trung bình. Tháng có biên độ dao động thấp nhất là tháng II với mức dao động $30,0 \mathrm{~mm}$.

Theo các kịch bản biến đồi khí hậu, nhiệt độ trung bình theo kịch bản RCP4.5 nhiệt độ trung bình tăng từ $0,6^{\circ} \mathrm{C}(2025)$ tăng đến $1,4^{\circ} \mathrm{C}(2050)$ và tăng $1,9^{\circ} \mathrm{C}(2100)$. Theo kịch bản RCP8.5 nhiệt độ trung bình tăng từ $0,7^{\circ} \mathrm{C}(2025)$ tăng đến $1,9^{\circ} \mathrm{C}(2050)$ và tăng $3,5^{\circ} \mathrm{C}(2100)$. Lượng mưa trung bình $(\mathrm{R})$ : Theo kịch bản RCP4.5, lượng mưa tăng từ 3,1\% (2025) tăng $3,5 \%(2050)$ và giảm đi $2,8 \%$ (2100). Theo kịch bản RCP8.5, lượng mưa tăng $9,1 \%(2025)$, giảm $9,3 \%$ (2050) và giảm $8,9 \%(2100)$.

Đóng góp của tác giả: Xây dựng ý tưởng nghiên cứu: N.V.H., N.T.C.M.; Lựa chọn phương pháp nghiên cứu: N.V.H., N.T.C.M.; Xử lý số liệu: N.V.H., N.T.C.M.; Viết bản thảo bài báo: N.V.H., N.T.C.M.; Chỉnh sửa bài báo: N.V.H.

Lời cam đoan: Tập thể tác giả cam đoan bài báo này là công trình nghiên cứu của tập thể tác giả, chưa được công bố ở đâu, không được sao chép từ những nghiên cứu trước đây; không có sự tranh chấp lợi ích trong nhóm tác giả.

\section{Tài liệu tham khảo}

1. Bộ Tài nguyên và Môi trường. Kịch bản Biến đổi Khí hậu, nước biển dâng cho Việt Nam. Nhà xuất bản Tài nguyên - Môi trường và Bản đồ Việt Nam, Hà Nội, 2009.

2. Bộ Tài nguyên và Môi trường. Kịch bản Biến đổi Khí hậu, nước biển dâng cho Việt Nam. Nhà xuất bản Tài nguyên - Môi trường và Bản đồ Việt Nam, Hà Nội, 2012.

3. Bộ Tài nguyên và Môi trường. Kịch bản Biến đổi khí hậu và nước biển dâng cho Việt Nam. Nhà xuất bản Tài nguyên - Môi trường và Bản đồ Việt Nam, 2016.

4. Phân viện Khoa học Khí tượng Thủy văn và Biến đổi khí hậu. Xây dựng, cập nhật kế hoạch hành động ứng phó với Biến đổi khí hậu giai đoạn 2021-2030, tầm nhìn 2050 và đánh giá khí hậu tỉnh Ninh Thuận. Sở TNMT Ninh Thuận, 2020.

5. Ngũ̃, N.Đ. Biến đổi khí hậu. Nhà xuất bản Khoa học và Kỹ thuật, Hà Nội, 2008.

6. Ban Quản lý dự án Capas Ninh Thuận. Báo cáo tài nguyên nước tỉnh Ninh Thuận. Tháng 7/2012.

7. Tuấn, B.Đ. Đặc điểm Khí tượng Thủy văn tỉnh Ninh Thuận. Phân viện Khoa học Khí tượng Thủy văn và Môi trường phía Nam, 2004.

8. Sở TNMT tỉnh Ninh Thuận. Báo cáo Hiện trạng Môi trường tỉnh Ninh Thuận 05 năm giai đoạn 2011-2015. Ninh Thuận, 2015.

9. UBND tỉnh Ninh Thuận. Báo cáo kinh tế-xã hội tỉnh Ninh Thuận, năm 2019.

10. Hà, H.T.M.; Tân, P.V. Xu thế và mức độ biến đổi của nhiệt độ cực trị ở Việt Nam trong giai đoạn 1961-2007. Tạp chí Khoa học, Đại học Quốc gia Hà Nội 2009, 25(3S), 412-422.

11. Hằng, V.T.; Hường, C.T.T.; Tân, P.V. Xu thế biến đổi của lượng mưa ngày cực đại ở Việt Nam giai đoạn 1961-2007. Tạp chi Khoa học, Đại học Quốc gia Hà Nội 2009, 25(3S), 423-430. 
12. Van den Hurk, B.; Siegmund, P.; Tank, A.K. Climate Change scenarios for the $21^{\text {st }}$ Century - A Netherlands perspective. Scientific Report WR2014-01, KNMI, De Bilt, The Netherlands, 2014.

13. IPCC. Climate Change: The Scientific Basis. Contribution of Working Group I to the Fourth Assessment Report of the Intergovernmental Panel on Climate Change, Cambridge University Press, Cambridge, United Kingdom and New York, NY, USA. 2007.

14. IPCC Fifth Assessment Report: Climate Change 2013 - The Physical Science Basis. Cambridge University Press, Cambridge, UK, 2013, 1535 pp.

15. IPCC. The Physical Science Basis. Contribution of Working Group I to the Fourth Assessment Report of the Intergovernmental Panel on Climate Change, 2007.

16. IPCC. The Physical Science Basis. Contribution of Working Group I to the Fifth Assessment Report of the Intergovernmental Panel on Climate Change, 2013.

17. Sâm, L. Nghiên cứu đánh giá tình hình hán, thiếu nước trong mùa khô, xây dựng phương án cảnh báo và bản đồ phân vùng hạn hán tỉnh Ninh Thuận. Viện khoa học thủy lợi miền Nam, 2008.

18. Thoại, N.S.; Bình, Đ.T. Tình hình hạn hán tại Ninh Thuận. Tạp chí Khí tượng Thủy văn 2013, 640, 46-49.

19. Vượng, N.Đ. Nghiên cứu tương quan cân bằng nước và đề xuất giải pháp cấp nước cho vùng đất cát ven biển Ninh Thuận. Viện khoa học thủy lợi miền Nam, 2013.

20. Kiệt, V.A. Nghiên cứu xây dựng hệ thống cảnh báo, dự báo chi tiết theo các cấp độ rủi ro thiên tai do bão, mưa lớn, lũ lụt, nắng nóng, hạn hán đến cấp xã (vùng), huyện thuộc tỉnh Ninh Thuận. Đề tài khoa học công nghệ cấp Tỉnh, 2018.

\title{
Climate Trends and Climate Change Scenarios in Ninh Thuan Province, Vietnam
}

\section{Nguyen Van Hong ${ }^{*}$, Nguyen Thi Cam Mi ${ }^{1}$}

${ }^{1}$ Sub-Institute HydoMeteogology and Climate Change; nguyenvanhong79@gmail.com; nguyenthicammi2007@gmail.com

\begin{abstract}
The study was presented the trend of climate (temperature, precipitation) in Ninh Thuan Province. The linear regression method is used to determine the trend and variation of past temperature and precipitation from 1993 to 2019 at Phan Rang meteorological stations. The results showed that the climate factors tend to increase: the annual average temperature for many years tends to increase by $0.012^{\circ} \mathrm{C} /$ year, the annual highest temperature increases by $0.017^{\circ} \mathrm{C} /$ year, the annual lowest minimum temperature increases by $0.01{ }^{\circ} \mathrm{C} /$ year, the precipitation increases by $4.44 \mathrm{~mm} /$ year. According to RCP4.5 and RCP8.5 climate change scenarios, the annual average temperature in Ninh Thuan tends to increase through 2025, 2030, 2050 and 2100. In terms of annual average precipitation for the RCP4.5 climate change scenario tends to increase. For the RCP 8.5 climate change scenario, the precipitation increases in 2025, 2030 and decreases and in 2050, 2100.
\end{abstract}

Keywords: Climate; Trend; Climate change Scenarios RCP4.5, RCP8.5. 